\title{
A Smartphone App for Self-Management of Heart Failure in Older African Americans: Feasibility and Usability Study
}

Sue P Heiney ${ }^{1}$, PhD, FAAN; Sara B Donevant ${ }^{1}$, PhD; Swann Arp Adams ${ }^{1}$, PhD; Pearman D Parker ${ }^{2}$, MPH, PhD; Hongtu Chen ${ }^{3}$, PhD; Sue Levkoff ${ }^{4}, \mathrm{SM}, \mathrm{MSW}, \mathrm{SCD}$

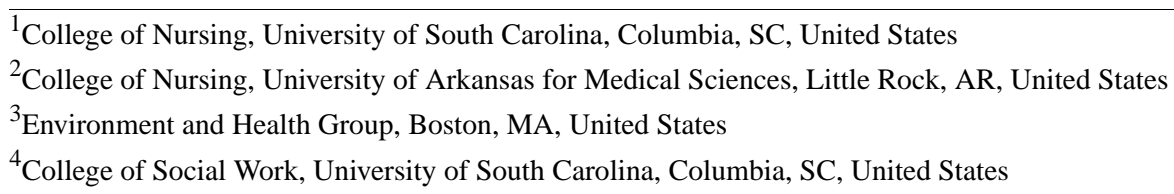

Corresponding Author:

Sue P Heiney, PhD, FAAN

College of Nursing

University of South Carolina

1601 Greene St

Columbia, SC, 29208

United States

Phone: 18037778214

Email: heineys@mailbox.sc.edu

\section{Abstract}

Background: Mobile health (mHealth) apps are dramatically changing how patients and providers manage and monitor chronic health conditions, especially in the area of self-monitoring. African Americans have higher mortality rates from heart failure than other racial groups in the United States. Therefore, self-management of heart failure may improve health outcomes for African American patients.

Objective: The aim of the present study was to determine the feasibility of using an mHealth app, and explore the outcomes of quality of life, including self-care maintenance, management, and confidence, among African American patients managing their condition after discharge with a diagnosis of heart failure.

Methods: Prior to development of the app, we conducted qualitative interviews with 7 African American patients diagnosed with heart failure, 3 African American patients diagnosed with cardiovascular disease, and 6 health care providers (cardiologists, nurse practitioners, and a geriatrician) who worked with heart failure patients. In addition, we asked 6 hospital chaplains to provide positive spiritual messages for the patients, since spirituality is an important coping method for many African Americans. These formative data were then used for creating a prototype of the app, named Healthy Heart. Specifically, the Healthy Heart app incorporated the following evidence-based features to promote self-management: one-way messages, journaling (ie, weight and symptoms), graphical display of data, and customized feedback (ie, clinical decision support) based on daily or weekly weight. The educational messages about heart failure self-management were derived from the teaching materials provided to the patients diagnosed with heart failure, and included information on diet, sleep, stress, and medication adherence. The information was condensed and simplified to be appropriate for text messages and to meet health literacy standards. Other messages were derived from interviews conducted during the formative stage of app development, including interviews with African American chaplains. Usability testing was conducted over a series of meetings between nurses, social workers, and computer engineers. A pilot one-group pretest-posttest design was employed with participants using the mHealth app for 4 weeks. Descriptive statistics were computed for each of the demographic variables, overall and subscales for Health Related Quality of Life Scale 14 (HQOL14) and subscales for the Self-Care of Heart Failure Index (SCHFI) Version 6 using frequencies for categorical measures and means with standard deviations for continuous measures. Baseline and postintervention comparisons were computed using the Fisher exact test for overall health and paired $t$ tests for HQOL14 and SCHFI questionnaire subscales.

Results: A total of 12 African American participants ( 7 men, 5 women; aged 51-69 years) diagnosed with heart failure were recruited for the study. There was no significant increase in quality of life $(P=.15)$, but clinically relevant changes in self-care maintenance, management, and confidence were observed. 
Conclusions: An mHealth app to assist with the self-management of heart failure is feasible in patients with low literacy, low health literacy, and limited smartphone experience. Based on the clinically relevant changes observed in this feasibility study of the Healthy Heart app, further research should explore effectiveness in this vulnerable population.

(JMIR Aging 2020;3(1):e17142) doi: 10.2196/17142

\section{KEYWORDS}

heart failure; mobile health app; self-management

\section{Introduction}

\section{Background}

Self-monitoring, generally defined as the awareness of symptoms through measurements, recordings, and observations, is foundational to the successful management of any chronic health condition. Mobile health (mHealth) apps are dramatically changing how patients and providers manage and monitor chronic health conditions, especially in the area of self-monitoring [1]. In particular, mHealth apps provide patients with quick and easy access to real-time health information to assist in making health decisions (ie, when to call the physician or go to the emergency department) and improve patient outcomes. Recent studies suggests that use of mHealth apps is associated with reductions in mortality and hospitalizations, along with improved adherence to therapy and enhanced quality of life [2,3].

\section{African American Patients With Heart Failure: A Vulnerable Population}

Adults with heart failure represent a particularly vulnerable population that may benefit from mHealth apps, especially African American adults living in rural communities. Currently, heart failure is the leading cause of hospitalization for older adults, which can lead to an increased risk of complications and health care costs $[4,5]$. The highest rates of hospitalization for patients with heart failure are reported in the southeast of the United States, including South Carolina [6]. In addition to high poverty levels, African American patients with heart failure may experience other challenges that negatively impact their health status, including lack of insurance, limited or no transportation, and an inadequate supply of health care providers [7]. Conversely, overall health could be improved if health care providers harness the cultural basis of self-care in the African American population, such as spirituality, social support, and nonbiomedical healing traditions [8].

The use of mHealth apps has successfully assisted in the self-management of patients with heart failure [9,10]. However, there is limited literature to support the use of mHealth in the African American population [11-14], with few heart failure mHealth apps designed specifically for this population, who are typically sicker, poorer, less educated, and more affected by comorbid conditions compared to other racial groups in the United States [15]. Therefore, there is a need for culturally appropriate mHealth apps to assist this vulnerable population of African American patients with heart failure.

The purpose of this study was to design and describe the feasibility of the Healthy Heart app in African American patients with a discharge diagnosis of heart failure and assess impacts of using the app on quality of life and self-care.

\section{App Development}

To overcome these concerns and limitations, our team developed a prototype app, termed Healthy Heart, through an iterative design process with input from end users (ie, patients with heart failure and health care providers). The team consisted of nurses, social workers, and computer engineers. We adopted the situation-specific theory for behavioral change, which emphasizes the following three key components of self-management: (1) self-monitoring of symptoms, which helps patient to notice and focus on specific health problems; (2) health literacy, which educates patients about the role of healthy behaviors leading to desirable health benefits; and (3) confidence (self-efficacy), which is associated with making behavioral changes and taking actions to manage and improve one's health [16]. App development was also guided by emerging mHealth research to deliver interventions for self-management by fostering the cognitive and behavioral changes necessary to promote stability, health, and well-being in patients with heart failure [17,18].

Prior to app development, we used purposeful sampling to recruit 7 African American patients with heart failure and 3 African American patients with cardiovascular disease for qualitative interviews about their experience with heart failure. We also recruited 6 health care providers (cardiologists, nurse practitioners, and a geriatrician) who worked with heart failure patients. Using these formative data, we created a prototype of the Healthy Heart app incorporating the following evidence-based features to promote self-management: one-way messages, journaling (ie, weight and symptoms), graphical display of data, and customized feedback (ie, clinical decision support) based on daily or weekly weight. Figure 1 displays screenshots of these main features. 
Figure 1. Screenshots of sample app features.

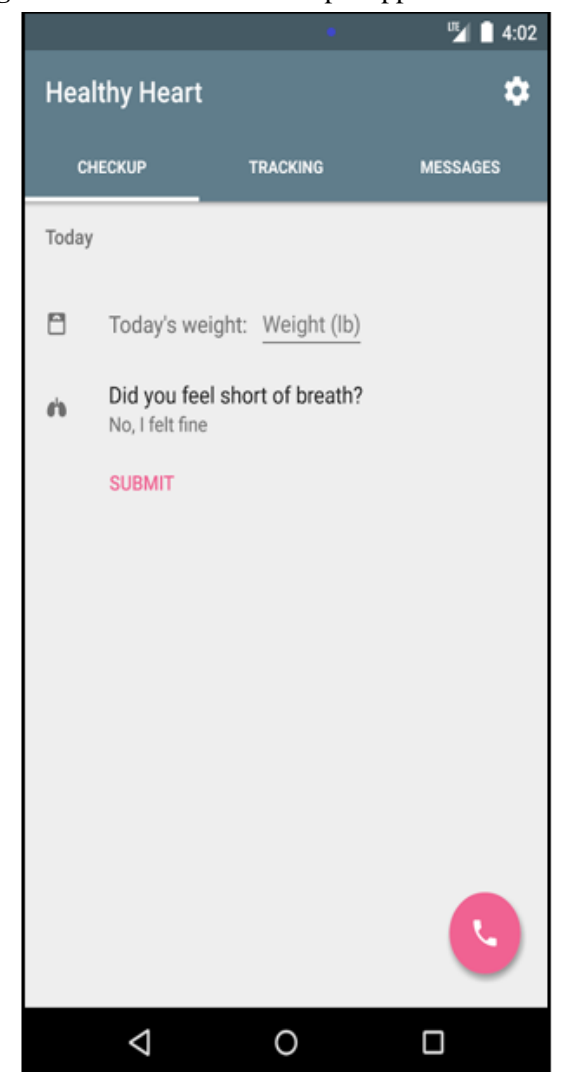

The educational messages about heart failure self-management were derived from the heart failure teaching material provided to patients diagnosed with heart failure, and included information on diet, sleep, stress, and medication adherence. Sources for patient teaching included Agency for Healthcare Research and Quality Heart Failure Communication Tools [19], Health Topics, Heart Failure [20], and How to Reduce Sodium [21]. The information was condensed and simplified to be appropriate for text messages and to meet health literacy standards. Other messages were derived from interviews conducted during the formative stage of app development, including interviews with 6 African American hospital chaplains. We involved chaplains at this stage because spirituality is an important component of African American culture. For example, one motivational message was "Even when we go through things God is always there to lead us through troubling times in our lives" paraphrased from Psalms 46. The team conducted usability testing over a series of meetings between the nurses, social worker, and computer engineers.

\section{Methods}

\section{Overview of Study Design}

In this quasiexperimental pilot study using a one-group pretest-posttest design, 12 African American participants with a discharge diagnosis of heart failure used the Healthy Heart app. Prior to start of the study, Internal Review Board approval was received from the University of South Carolina and a locally owned, not-for-profit health care system.

\section{Recruitment and Retention}

Inclusion criteria were English-speaking African American men or women aged 50 years or older who received a diagnosis of heart failure and were discharged from the hospital to home care. Patients were excluded if they had a major cognitive impairment or a current diagnosis of psychosis. The home health nurse did not use a screening tool to determine cognitive impairment but instead used the discharge summary and her clinical judgment with the participant and family. Subjects who could not speak either English or a dialect of English were also excluded. Patients younger than 50 years of age were excluded from the study with no restriction on the upper age for participants.

The pool of potential participants comprised patients diagnosed with heart failure and discharged from the locally owned, not-for-profit health care system receiving 30 days of home health telemonitoring (ie, standard of care). Home health telemonitoring included an interactive monitor with direct connections to a scale and blood pressure cuff that automatically uploaded the data to a home health nurse. However, no additional visits were made to the patients after the monitor was installed and set up. The patients received telephone communication with the nurse if any of the measures were abnormal.

The home health nurses collaborated with the study team by querying the telemonitored patients of interest in participating in the Healthy Heart app study. Based on collaboration with the home health facility, we were unable to collect data about the number of patients approached. Recruitment occurred between November 2015 and September 2016. If interested, the patient signed a Health Information Portability and Accountability Act 
release, which included contact information for the study coordinator, and received a fact sheet about the study. The study coordinator called the participants for a phone discussion that summarized and explained the study details, including the purpose, procedures, risks, benefits, and voluntary participation. Potential participants were encouraged to ask any questions. If the participant was interested, an appointment was scheduled for the study coordinator to visit the participant's home to obtain consent and administer the baseline study assessments. All participants were provided with an Android phone with the Healthy Heart app (ie, intervention) installed. This provided consistency and ease of instructing the participants on using the app. No monetary compensation was offered to the study participants; however, they were able to keep the low-cost study phone after the study period. In addition, a small thank you postcard and gift (approximately $\$ 1$ value) was mailed to the participants weekly to promote retention in the study.

\section{Procedures}

Once the study coordinator received verbal consent from the participant during the telephone conversations, the first home visit was scheduled within approximately 2 weeks after hospital discharge while the patient was still receiving telemonitoring from the home care nurse. During this home visit, the study coordinator obtained all baseline data.

A second home visit occurred approximately 1 week later in which the participant received the prepaid activated phone. The coordinator educated the participant about using the phone and Healthy Heart app. The study coordinator spent time teaching the participant (and caregiver if desired) how to turn the phone on and off, how to charge the battery, how to open the Healthy Heart app, and so forth. The US Department of Health and Human Services reports nearly 9 out of 10 adults in the United States have difficulty using everyday health information, and South Carolina ranks 39th in literacy in the country [22]. Based on our previous work with low-literacy, low-health literacy, and low-digital literacy patients, we anticipated that these participants would have low familiarity with using a smartphone or an app. Indeed, 7 of the 12 participants did not previously own a smartphone. Thus, we designed an instruction booklet written at a sixth-grade or lower reading level and used screenshots to explain each operation of the phone and each function of the app. In addition, the study coordinator assisted the participants with entering the phone numbers of the health care provider and pharmacy. On average, these visits lasted 1-2 hours. This home visit was timed so that the participant would have 1 week of overlap with the home health telemonitoring (ie, standard of care) and start of self-monitoring via the Healthy Heart app (ie, intervention). This overlap allowed the participants to become familiar with the app before stopping the telemonitoring for a seamless transition. The participant was instructed to call the coordinator if any questions arose. The coordinator called the participants about 2 weeks after the initial training to ascertain if they were experiencing any difficulties using the phone and the app. No additional visits for training occurred, but the coordinator was available during normal business hours via phone to assist with any usability or technical issues.
Six weeks after the initial assessment, a final assessment was completed, including the completion of assessment instruments obtained at baseline, the participants' perceptions of the phone and Healthy Heart app, and retrieval of data.

\section{Description of the Intervention}

The intervention consisted of the use of all app features continuously over 4 weeks. A total of 3 messages were sent daily: (1) a reminder to weigh every morning, (2) an educational message, and (3) motivational messages. Messages were repeated when the message bank had sent all messages once. The other two components of the app were journaling and customized feedback. Journaling consisted of the participant entering a daily weight and responding to a question about shortness of breath. The final component was customized feedback (ie, clinical decision support) that sent an alert message if the weight exceeded standards set by the home health protocol for monitoring heart failure. The message instructed the participant to call the health care provider if they experienced an increase of 2-3 pounds in a day or over 5 pounds in a week. Regardless of the amount of weight gained or lost, the participant could view a weekly graph of weight fluctuations.

\section{Data Collection}

Demographic and personal data were collected using a demographic data form adapted from a previous study [23]. Examples of personal data include living situation, instrumental social support, years since diagnosis, phone type, insurance type, and faith group. In addition, the participants were interviewed to ascertain their current recall of prior teaching on heart failure and current information on how to handle heart failure-related concerns. The interview consisted of yes/no and open-ended questions (eg, "Has anyone talked with you about the things you need to know in order to take care of yourself and your heart?").

The 14-item Centers for Disease Control and Prevention (CDC) Health Related Quality of Life Scale 14 (HRQOL14) was used to assess the participants' quality of life [24]. This scale has strong validity and reliability [25]. The following three modules of the HRQOL14 were utilized: core healthy days, activity limitations, and healthy days symptoms. The core healthy days (4 items) assessed (1) perceived general health, (2) number of days when physical health was perceived as poor, (3) number of days when mental health was perceived as poor, and (4) number of days when the respondent perceived activity limitations due to poor mental or physical health. Instructions for scoring followed the CDC guidelines [24]. The activity limitations module assessed more details about activity limitations due to poor health, including personal care and routine needs. The healthy days symptoms module was assessed only if the participant responded "no" to the activity limitation item in the healthy days module. For both the activity limitations and healthy days symptoms modules, we used the CDC Statistical Analysis System syntax for scoring [26].

The Self-Care of Heart Failure Index (SCHFI) Version 6 [16,27-29] subjectively assesses the participant in three areas: maintenance, management, and self-confidence, which are based on Riegel and Dickson's [16] conceptual model of heart failure 
self-care. The instrument consists of 22 items rated on a 4-point scale with each subscale scored separately. Barbaranelli et al [27] recommended against reporting an overall score when a participant does not have a certain number of problems. The raw score ranges for each subscale are as follows: 10-40 for self-care maintenance, 4-24 for management, and 6-26 for self-care confidence. These ranges were all standardized to 0-100. Instructions for scoring and methods for handling missing data followed the method of Riegel and colleagues [28]. Reliability of the subscales ranged from low to adequate $(\alpha=0.56-0.80)$ and construct validity was adequate [29].

\section{Analysis}

Descriptive statistics were computed for each of the demographic variables, overall and subscales for HQOL14, and subscales for the SCHFI using frequencies for categorical variables and means (SD) for continuous variables. Baseline and postintervention comparisons were computed using the Fisher exact test for overall health and with paired $t$ tests for HQOL14 and SCHFI subscales.

\section{Results}

\section{Recruitment}

We enrolled 12 African American participants for this feasibility study. One participant was lost to follow up at the second assessment. Thus, 11/12 (92\%) participants completed the study.

\section{Demographic and Health Characteristics of the Sample}

The main characteristics of our sample are summarized in Table 1. There were more men than women, and the age of participants ranged from 51 to 69 years. One quarter of the participants were married and the remaining participants were single, divorced, separated, or widowed. The majority of participants (10/12, $83 \%)$ graduated from high school. Over half of the participants $(8 / 12,67 \%)$ preferred not to answer about income or did not know their income. One third of the participants were on Medicare or Medicaid (4/12), one third had no insurance (4/12), one fourth had private insurance, and one third (4/12) did not know about insurance coverage. All participants $(12 / 12,100 \%)$ reported belonging to a church. Eleven of the 12 participants (92\%) owned a cell phone, and 5/12 (42\%) owned a smartphone. The majority of the participants received a diagnosis of heart failure less than one year prior to the study $(7 / 12,58 \%)$.

Table 1. Demographic and health characteristics of the study population $(\mathrm{N}=12)$.

\begin{tabular}{|c|c|}
\hline Variable & Value \\
\hline Age (years), mean (SD) & $57.83(1.68)$ \\
\hline \multicolumn{2}{|l|}{ Gender, n (\%) } \\
\hline Male & $7(58)$ \\
\hline Female & $5(42)$ \\
\hline \multicolumn{2}{|l|}{ Marital status, n (\%) } \\
\hline Married & $3(25)$ \\
\hline Not married & $9(75)$ \\
\hline \multicolumn{2}{|l|}{ Education, n (\%) } \\
\hline Less than high school & $2(17)$ \\
\hline High school & $7(58)$ \\
\hline More than high school & $3(25)$ \\
\hline \multicolumn{2}{|l|}{ Income, n (\%) } \\
\hline Do not know & $2(17)$ \\
\hline Less than $\$ 10,000$ & $3(25)$ \\
\hline$\$ 30,000-\$ 39,999$ & $1(8)$ \\
\hline Chose not to answer & $6(50)$ \\
\hline \multicolumn{2}{|l|}{ Years since diagnosis, $\mathbf{n}(\%)$} \\
\hline$<1$ & $7(58)$ \\
\hline 2 to 8 & $3(25)$ \\
\hline 11 to 13 & $2(17)$ \\
\hline
\end{tabular}

\section{Heart Failure Care Activities}

In the baseline assessment, most participants $(11 / 12,92 \%)$ stated that their health care provider (ie, doctor, nurse, or dietician) had discussed ways to manage their heart failure. All participants reported weighing themselves daily, but 3/12 (25\%) noted that they did not record their weight regularly. Six participants $(50 \%)$ received instruction on specific limits for fluid intake and provided examples of 40 ounces, a quart, a gallon, or a liter. 
However, only 5/12 (42\%) participants reported that they followed the recommended fluid restriction. Participants gave a variety of answers when asked about salt restriction (eg, restricted salt altogether, do not eat much salt, or restricted to $200 \mathrm{mg}$ per day).

\section{Feasibility of App Usage}

Participants with low digital literacy (ie, nonadopters of digital technology) initially struggled with phone and app operation. Anticipating this prior to phone distribution, we removed all nonessential apps from the phone to alleviate confusion about which app to use: the distributed phone only included the ability to call, a search engine app, and the Healthy Heart app. Nevertheless, participants had to practice several times during the training to understand how to answer the phone, make a phone call, and open the app. They also needed to use the instruction booklet to help remember these steps in operating the phone. In spite of these barriers, over $60 \%$ of the data were successfully collected.

At the end of the intervention, we evaluated the participants' use of the phone and app to assist with future iterations of the app as well as to guide future research in working with this population. Unfortunately, we were unable to identify an evaluation tool specifically for mHealth apps and this population. For example, the Systems Usability Scale [30,31] was too broad to help us identify specific problems with the phone and the app. We asked closed questions that assessed potential problems with the phone and messages (ie, readability), and these results are summarized in Table 2.

Table 2. Postintervention experience with the project and phone usage $(\mathrm{N}=11)$.

\begin{tabular}{|c|c|c|}
\hline Question & Response & $\mathrm{n}(\%)$ \\
\hline Did you have any difficulty using the phone? & No & $6(55)$ \\
\hline Was it easy to charge the phone? & Yes & $10(91)$ \\
\hline Was it easy to read the message? & Yes & $11(100)$ \\
\hline Was the font (size of the print) big enough? & Yes & $10(91)$ \\
\hline Was the length of the message too long, not long enough, just right? & Just right & $10(91)$ \\
\hline Have you used the phone to go online (search the web)? & Yes & $4(36)$ \\
\hline Have you made any phone calls with this phone? & Yes & $10(91)$ \\
\hline Have you sent any text messages? & Yes & $4(36)$ \\
\hline Have you seen the Quick Dial feature (ie, that you can press to call your health providers)? & Yes & $5(46)$ \\
\hline If yes, have you ever used the Quick Dial feature? & Yes & $2(18)$ \\
\hline If not, would you use it if you need to contact your providers? & Yes & $6(55)$ \\
\hline
\end{tabular}

\section{Quality of Life and Self-Care Heart Failure Index}

For HRQOL14, at baseline, 5/12 (42\%) of participants reported that their overall health was poor or fair, whereas at the postintervention assessment, 2/11 (18\%) rated their health as poor or fair. No significant changes were found for any of the HQOL14 subscales. At baseline, participants reported a mean of 4 (SD 5.75, range 0-14) physically unhealthy days. Postintervention, the mean number of unhealthy days was reduced to 2.54 (SD 4.32, range 0-15). At baseline, respondents reported a mean of 1.42 mentally unhealthy days (SD 2.39, range 0-7), which increased postintervention to 3.18 (SD 9.02, range 0-30). At baseline, the mean number of days participants reported experiencing limitation in daily activities due to poor physical or mental health was 2.58 (SD 3.03, range 0-8), which decreased postintervention to 1.73 (SD 3.00, range 0-10). The mean preintervention combined physical and mental unhealthy days was 5.41 (SD 7.54, range 0-21), which was similar to that postintervention at 5.54 (SD 9.95, range 0-30).

For the SCHFI, we were not able to analyze the management subscale due to participant responses. Per Riegel et al [28], if a participant responded "no" to experiencing trouble breathing or ankle swelling in the past month, then the management section of the SCHFI was not scored. Only 5/12 (42\%) participants reported problems with one of these symptoms. Therefore, we compared baseline and postintervention scores for maintenance and confidence. No significant differences were found on either subscale. However, based on Riegel et al [28], the maintenance, management, and self-confidence scales showed clinically relevant improvement from baseline to posttest as the difference in the mean baseline score for maintenance and management was greater than 8 (Table 3 ). 
Table 3. Analysis of subscales of Self-Care of Heart Failure Index.

\begin{tabular}{llllll}
\hline Subscale & Baseline, mean (SD) & Postintervention, mean (SD) & $P$ value & Difference score & Clinically relevant $^{\mathrm{a}}$ \\
\hline Maintenance $(\mathrm{N}=12)$ & $63.33(15.50)$ & $72.70(15.62)$ & .15 & 9.37 & Yes \\
Management $(\mathrm{N}=9)$ & $70.0(7.07)$ & $85.00(14.36)$ & Presample too small ${ }^{\mathrm{b}}$ & 15.00 & Yes \\
Confidence $(\mathrm{N}=12)$ & $83.86(13.51)$ & $90.90(10.90)$ & .17 & 7.04 & Approaches \\
\hline
\end{tabular}

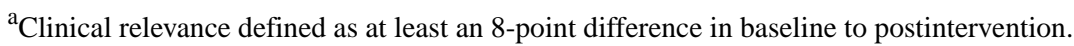

${ }^{\mathrm{b}}$ At least half the items were missing from participant responses.

\section{Hospital Readmission and Emergency Room Visits}

During the final assessment, we ascertained information about emergency room and hospital readmissions. One participant reported admission to the hospital via the emergency room and another other participant reported an emergency room visit during the 6 weeks of the study. Six participants called their provider at least once based on instructions from the app.

\section{Discussion}

\section{Feasibility}

When working with a digitally naïve population with low literacy, we recommend careful consideration of the phone display (ie, simple and uncluttered) and the use of simple instructional materials. The use of screenshots instead of text in the instructional materials seemed to help participants understand how to use the phone and app. Although such work may be challenging, more research is needed on designing mHealth for this population. Our study makes a significant contribution toward the use of mHealth apps for managing a chronic disease in a health-disparate population. In this regard, we substantiated the work by Cajita et al [32] showing that older adults are willing to use mHealth technology.

\section{Exploratory Findings}

The Healthy Heart app did not significantly increase quality of life $(P=.15)$, but did show clinically relevant changes in heart failure self-care maintenance, management, and confidence. Our preliminary findings are similar to those of Dang et al [33] who identified that an mHealth app is a feasible method of assisting health-disparate patients to manage their disease. However, in contrast to the results of their randomized controlled trial [34], our study participants showed clinically relevant changes in their ability to maintain and respond to heart failure symptoms, but did not show significant improvements in self-efficacy or quality of life.

The participants in our study had low rates of hospital readmissions and emergency room visits. This finding is consistent with a systematic review showing that that mHealth apps to manage heart failure may reduce heart failure-related hospital days [35]. However, our baseline findings regarding participant understanding are inconsistent with those of Spaling et al [36] who found that patients could recall advice about self-care. Our participants' recall was not clear and often contained vague information. Our participants showed similar improvement in self-care to that found in the Spaling et al [36] study, although our change was not statistically significant.

\section{Limitations}

One limitation of the study is that we only tested the intervention (use of the app) for 4 weeks. This may not have allowed enough time for behavioral changes to be established and influence quality of life. Other limitations include the small sample size and the quasiexperimental nature of the study. However, previous studies suggest that a quasiexperimental design is appropriate when participants are unlikely to change their behavior without an intervention (ie, inclusion of a usual care group would not add information during pilot testing) [37,38]. Further, the impact of prior experience with telemonitoring (ie, standard of care) could have influenced the outcomes of this study. However, since we collected baseline data at the end of telemonitoring, we feel confident that our data reflected important improvements related to the use of the Healthy Heart app.

\section{Conclusions}

This study provides insights into the feasibility of mHealth apps among a disparate population with low literacy, low health literacy, and limited smartphone use. Additionally, the study provides essential lessons for the use of mHealth apps in this population. Providing instructions with screenshots with minimal text was a successful technique for training the participants on using the smartphone and Healthy Heart app. Furthermore, the inclusion of culturally appropriate messages potentially enhanced the acceptance of the Healthy Heart app. The initial focus groups with African American patients guided the development of the mHealth app to include culturally appropriate content. These findings suggest that patients want content that recognizes cultural differences. This study demonstrated clinically relevant changes in heart failure self-care maintenance, management, and confidence. As mHealth technology continues to advance, it is important to take into account how to address the needs of all patients, including those with low literacy, low health literacy, and limited smartphone use, as well as cultural differences. This study can provide some guidance on addressing these challenges for unique patient populations. 


\section{Acknowledgments}

This study was funded by the National Institutes of Health (1 R43 HL115924-01). We would like to thank Jessica Williams, BSN, RN (Prisma Midlands Home Health) who assisted with this study as a telemonitoring nurse.

\section{Authors' Contributions}

SH helped in conducting the study, data analysis, and writing and review of the article. SD and SA were involved in data analysis and writing and review of the article. PP was involved in conducting the study and writing and review of the article. HC and SL were involved in study concept, writing the grant, and writing and review of the article.

\section{Conflicts of Interest}

SH, SD, SA, PP, and HC have no conflicts to declare. SL has equity in the Health and Environment Group that received the grant.

\section{References}

1. Coorey GM, Neubeck L, Mulley J, Redfern J. Effectiveness, acceptability and usefulness of mobile applications for cardiovascular disease self-management: Systematic review with meta-synthesis of quantitative and qualitative data. Eur J Prev Cardiol 2018 Mar;25(5):505-521. [doi: 10.1177/2047487317750913] [Medline: 29313363]

2. Klersy C, De Silvestri A, Gabutti G, Regoli F, Auricchio A. A meta-analysis of remote monitoring of heart failure patients. J Am Coll Cardiol 2009 Oct 27;54(18):1683-1694 [FREE Full text] [doi: 10.1016/j.jacc.2009.08.017] [Medline: 19850208]

3. Clarke M, Shah A, Sharma U. Systematic review of studies on telemonitoring of patients with congestive heart failure: a meta-analysis. J Telemed Telecare 2011;17(1):7-14. [doi: 10.1258/jtt.2010.100113] [Medline: 21097564]

4. Jencks SF, Williams MV, Coleman EA. Rehospitalizations among patients in the Medicare fee-for-service program. N Engl J Med 2009 Apr 02;360(14):1418-1428. [doi: 10.1056/NEJMsa0803563] [Medline: 19339721]

5. Emani S. Remote Monitoring to Reduce Heart Failure Readmissions. Curr Heart Fail Rep 2017 Feb;14(1):40-47. [doi: 10.1007/s11897-017-0315-2] [Medline: 28215030]

6. Casper M, Nwaise I, Croft JB, Hong Y, Fang J, Greer S. Geographic disparities in heart failure hospitalization rates among Medicare beneficiaries. J Am Coll Cardiol 2010 Jan 26;55(4):294-299 [FREE Full text] [doi: 10.1016/j.jacc.2009.10.021] [Medline: 20117432]

7. Dickson VV, McCarthy MM, Howe A, Schipper J, Katz SM. Sociocultural influences on heart failure self-care among an ethnic minority black population. J Cardiovasc Nurs 2013;28(2):111-118. [doi: 10.1097/JCN.0b013e31823db328] [Medline: 22343210]

8. Becker G, Gates RJ, Newsom E. Self-care among chronically ill African Americans: culture, health disparities, and health insurance status. Am J Public Health 2004 Dec;94(12):2066-2073. [doi: 10.2105/ajph.94.12.2066] [Medline: 15569953]

9. Aamodt IT, Lycholip E, Celutkiene J, von Lueder T, Atar D, Falk RS, et al. Self-Care Monitoring of Heart Failure Symptoms and Lung Impedance at Home Following Hospital Discharge: Longitudinal Study. J Med Internet Res 2020 Jan 07;22(1):e15445 [FREE Full text] [doi: 10.2196/15445] [Medline: 31909717]

10. Lefler LL, Rhoads SJ, Harris M, Funderburg AE, Lubin SA, Martel ID, et al. Evaluating the Use of Mobile Health Technology in Older Adults With Heart Failure: Mixed-Methods Study. JMIR Aging 2018 Dec 04;1(2):e12178 [FREE Full text] [doi: 10.2196/12178] [Medline: 31518257]

11. Barnason S, Zimmerman L, Young L. An integrative review of interventions promoting self-care of patients with heart failure. J Clin Nurs 2012 Feb;21(3-4):448-475. [doi: 10.1111/j.1365-2702.2011.03907.x] [Medline: 22098479]

12. Radhakrishnan $\mathrm{K}$, Jacelon $\mathrm{C}$. Impact of telehealth on patient self-management of heart failure: a review of literature. $\mathrm{J}$ Cardiovasc Nurs 2012;27(1):33-43. [doi: 10.1097/JCN.0b013e318216a6e9] [Medline: 21558862]

13. Grustam AS, Severens JL, van Nijnatten J, Koymans R, Vrijhoef HJM. Cost-effectiveness of telehealth interventions for chronic heart failure patients: a literature review. Int J Technol Assess Health Care 2014 Jan;30(1):59-68. [doi: 10.1017/S0266462313000779] [Medline: 24495581]

14. Thokala P, Baalbaki H, Brennan A, Pandor A, Stevens JW, Gomersall T, et al. Telemonitoring after discharge from hospital with heart failure: cost-effectiveness modelling of alternative service designs. BMJ Open 2013 Sep 18;3(9):e003250 [FREE Full text] [doi: 10.1136/bmjopen-2013-003250] [Medline: 24048626]

15. Boutwell A, Hwu S. Institute for Healthcare Improvement. 2009. Effective interventions to reduce rehospitalizations: a survey of the published evidence URL: https://tinyurl.com/wotwlrp [accessed 2020-02-22]

16. Riegel B, Dickson VV. A situation-specific theory of heart failure self-care. J Cardiovasc Nurs 2008;23(3):190-196. [doi: 10.1097/01.JCN.0000305091.35259.85] [Medline: 18437059 ]

17. Nundy S, Razi RR, Dick JJ, Smith B, Mayo A, O'Connor A, et al. A text messaging intervention to improve heart failure self-management after hospital discharge in a largely African-American population: before-after study. J Med Internet Res 2013;15(3):e53 [FREE Full text] [doi: 10.2196/jmir.2317] [Medline: 23478028]

18. Hughes HA, Granger BB. Racial disparities and the use of technology for self-management in blacks with heart failure: a literature review. Curr Heart Fail Rep 2014 Sep;11(3):281-289 [FREE Full text] [doi: 10.1007/s11897-014-0213-9] [Medline: $\underline{25012939]}$ 
19. Agency for Health Care Research and Quality. 2007. Red-yellow-green congestive heart failure (CHF) tool URL: https:/ /innovations.ahrq.gov/qualitytools/red-yellow-green-congestive-heart-failure-chf-tool [accessed 2020-02-29]

20. National Heart Lung and Blood Institute. Heart Failure URL: https://www.nhlbi.nih.gov/health-topics/heart-failure [accessed 2020-02-05]

21. American Heart Association. 2018 May 23. How to reduce sodium URL: https://www.heart.org/en/healthy-living/ healthy-eating/eat-smart/sodium/how-to-reduce-sodium [accessed 2020-02-05]

22. Greenho K. Reading Partners. South Carolina still lagging in literacy URL: https://readingpartners.org/news/ south-carolina-still-lagging-in-literacy/ [accessed 2020-03-25]

23. Heiney SP, Millon Underwood S, Tavakoli A, Arp Adams S, Wells LM, Bryant LH. Randomized trial of therapeutic group by teleconference: African American women with breast cancer. Cancer 2012 Aug 01;118(15):3822-3832. [doi: 10.1002/cncr.26676] [Medline: 22180125]

24. Centers for Disease Control and Prevention. Health Related Quality of Life. 2018. CDC HRQOL-14 "Healthy Days Measure" URL: https://www.cdc.gov/hrqol/hrqol14_measure.htm [accessed 2020-02-05]

25. Centers for Disease Control and Prevention. Health Related Quality of Life. CDC Health Related Quality of Life URL: https://www.cdc.gov/hrqol/index.htm [accessed 2020-02-05]

26. Centers for Disease Control and Prevention. US Department of Health and Human Service. 2000. Measuring healthy days: population assessment of health-related quality of life URL: https://www.cdc.gov/hrqol/pdfs/mhd.pdf [accessed 2020-02-05]

27. Barbaranelli C, Lee CS, Vellone E, Riegel B. Dimensionality and reliability of the self-care of heart failure index scales: further evidence from confirmatory factor analysis. Res Nurs Health 2014 Dec;37(6):524-537 [FREE Full text] [doi: 10.1002/nur.21623] [Medline: 25324013]

28. Riegel B, Lee CS, Dickson VV, Carlson B. An update on the self-care of heart failure index. J Cardiovasc Nurs 2009;24(6):485-497 [FREE Full text] [doi: 10.1097/JCN.0b013e3181b4baa0] [Medline: 19786884]

29. Riegel B, Carlson B, Moser DK, Sebern M, Hicks FD, Roland V. Psychometric testing of the self-care of heart failure index. J Card Fail 2004 Aug;10(4):350-360. [doi: 10.1016/j.cardfail.2003.12.001] [Medline: 15309704]

30. Sauro J. Measuring U. Measuring usability with the System Usability Scale (SUS) URL: https://measuringu.com/sus/ [accessed 2020-03-25]

31. Brooke J. SUS- a quick and dirty usability scale. In: Jordan PW, Thomas B, Weerdmeester BA, McClelland AL, editors. Usability Evaluation In Industry. London: Taylor and Fracis; 1996.

32. Cajita MI, Hodgson NA, Lam KW, Yoo S, Han H. Facilitators of and Barriers to mHealth Adoption in Older Adults With Heart Failure. Comput Inform Nurs 2018 Aug;36(8):376-382. [doi: 10.1097/CIN.0000000000000442] [Medline: 29742549]

33. Dang S, Karanam C, Gómez-Orozco C, Gómez-Marín O. Mobile Phone Intervention for Heart Failure in a Minority Urban County Hospital Population: Usability and Patient Perspectives. Telemed J E Health 2017 Dec;23(7):544-554. [doi: 10.1089/tmj.2016.0224] [Medline: 28051761]

34. Dang S, Karanam C, Gómez-Marín O. Outcomes of a Mobile Phone Intervention for Heart Failure in a Minority County Hospital Population. Telemed J E Health 2017 Jun;23(6):473-484. [doi: 10.1089/tmj.2016.0211] [Medline: 28051357]

35. Carbo A, Gupta M, Tamariz L, Palacio A, Levis S, Nemeth Z, et al. Mobile Technologies for Managing Heart Failure: A Systematic Review and Meta-analysis. Telemed J E Health 2018 Apr 02. [doi: 10.1089/tmj.2017.0269] [Medline: 29608430]

36. Spaling MA, Currie K, Strachan PH, Harkness K, Clark AM. Improving support for heart failure patients: a systematic review to understand patients' perspectives on self-care. J Adv Nurs 2015 Nov;71(11):2478-2489. [doi: 10.1111/jan.12712] [Medline: 26084885]

37. Bowen DJ, Kreuter M, Spring B, Cofta-Woerpel L, Linnan L, Weiner D, et al. How we design feasibility studies. Am J Prev Med 2009 May;36(5):452-457 [FREE Full text] [doi: 10.1016/j.amepre.2009.02.002] [Medline: 19362699]

38. Czajkowski SM, Powell LH, Adler N, Naar-King S, Reynolds KD, Hunter CM, et al. From ideas to efficacy: The ORBIT model for developing behavioral treatments for chronic diseases. Health Psychol 2015 Oct;34(10):971-982 [FREE Full text] [doi: 10.1037/hea0000161] [Medline: 25642841]

\author{
Abbreviations \\ CDC: Centers for Disease Control and Prevention \\ HRQL14: Health Related Quality of Life Scale 14 \\ mHealth: mobile health \\ SCHFI: Self-Care of Heart Failure Index
}


Edited by L Song; submitted 26.11.19; peer-reviewed by L Lefler, E Ding; comments to author 29.12.19; revised version received 26.02.20; accepted 12.03.20; published 03.04.20

Please cite as:

Heiney SP, Donevant SB, Arp Adams S, Parker PD, Chen H, Levkoff S

A Smartphone App for Self-Management of Heart Failure in Older African Americans: Feasibility and Usability Study JMIR Aging 2020;3(1):e17142

URL: http://aging.jmir.org/2020/1/e17142/

doi: $10.2196 / 17142$

PMID: $\underline{32242822}$

(C) Sue P Heiney, Sara B Donevant, Swann Arp Adams, Pearman D Parker, Hongtu Chen, Sue Levkoff. Originally published in JMIR Aging (http://aging.jmir.org), 03.04.2020. This is an open-access article distributed under the terms of the Creative Commons Attribution License (https://creativecommons.org/licenses/by/4.0/), which permits unrestricted use, distribution, and reproduction in any medium, provided the original work, first published in JMIR Aging, is properly cited. The complete bibliographic information, a link to the original publication on http://aging.jmir.org, as well as this copyright and license information must be included. 